\title{
Natural anti-inflammatory terpenoids in Camellia japonica leaf and probable biosynthesis pathways of the metabolome
}

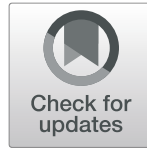

\author{
Soumya Majumder, Arindam Ghosh and Malay Bhattacharya * (D)
}

\begin{abstract}
Background: Metabolomics of Camellia japonica leaf has been studied to identify the terpenoids present in it and their interrelations regarding biosynthesis as most of their pathways are closely situated. Camellia japonica is famous for its anti-inflammatory activity in the field of medicines and ethno-botany. In this research, we intended to study the metabolomics of Camellia japonica leaf by using gas chromatography-mass spectroscopy technique.

Results: A total of twenty-nine anti-inflammatory compounds, occupying $83.96 \%$ of total area, came out in the result. Most of the metabolites are terpenoids leading with triterpenoids like squalene, lupeol, and vitamin E. In this study, the candidate molecules responsible for anti-inflammatory activity were spotted out in the leaf extract and biosynthetic relation or interactions between those components were also established.

Conclusion: Finding novel anticancer and anti-inflammatory medicinal compounds like lupeol in a large amount in Camellia japonica leaf is the most remarkable outcome of this gas chromatography-mass spectroscopy analysis. Developing probable pathway for biosynthesis of methyl commate B is also noteworthy.
\end{abstract}

Keywords: Camellia japonica, Metabolomics, GC-MS, Anti-inflammatory compounds, Lupeol

\section{Background}

Inflammation in the body is a result of a natural response to injury which induces pain, fever, and swelling. Both corticosteroids and non-steroidal anti-inflammatory drugs are used to reduce this pain by acting on the anti-inflammatory pathways. But these drugs have undesirable side effects as gastric ulceration, infrequently myocardial infarction, and stroke (Maroon et al. 2010). For centuries, many plant and animal-derived natural compounds have been used to treat inflammation. Those compounds as dietary supplements and herbal remedies are becoming increasingly popular because of their relatively few side effects unlike steroidal and nonsteroidal anti-inflammatory drugs.

Camellia japonica is an ornamental flowering plant belongs to the family Theaceae. The wild plants of the

\footnotetext{
* Correspondence: malaytsnbu@gmail.com

Molecular Biology and Tissue Culture Laboratory, Department of Tea Science, University of North Bengal, Rajarammohanpur, Siliguri, Darjeeling 734013,
} India

genus Camellia originated in China (Shandong, east Taiwan, southern Korea, and southern Japan and China Antioxidant and anti-inflammatory activities of Camellia japonica leaves are already reported and this plant is proved to be a source of triterpenes, flavonoids, tannin, and fatty acids having antiviral, antioxidant, and anti-inflammatory activities (Lee et al. 2017). Seed from this plant is used as a traditional medicine and in folk is reported to have a high concentration of vitamin $\mathrm{E}$ ( n-eicosane $(10.2 \%)$ with other six active compo(neophytadiene; all trans-squalene; n-octacosane, 6,9pentadecadien-1-ol, $\alpha$-linolenic acid, and n-hexadecanoic acid) related to hyperuricemia (Yoon et al. 2017). However, 
the seed oil of this plant is already established as a medicinal ingredient in the pharmaceutical and food industry (Akihisa et al. 1997). Camellianoside is a quercetin Oglucoside isolated from the leaves of Camellia japonica and exhibits antioxidant activity. It has a role as a metabolite and a radical scavenger (Onodera et al. 2006). Our present investigation aimed to make a GC-MS analysis of Camellia japonica leaf extract to find out the compounds involved in exhibiting anti-inflammatory activity and study the pathways involved in their synthesis. The application of pathway study in this phytochemical analysis is an innovative strategy for targeting active compounds from this plant extract.

\section{Methods}

\section{Sample collection and preparation}

Healthy leaves were collected from an organically cultivated Camellia japonica plant, which was collected from Darjeeling Himalaya. Leaves of Camellia japonica were crushed in liquid nitrogen and mixed in methanol (widely used solvent for extraction) to make Camellia japonica leaf extract (CJLE). The extract was left overnight on a shaker at $25^{\circ} \mathrm{C}$. The extract was centrifuged and the supernatant was collected for GC-MS analysis.

\section{Gas chromatography-mass spectrometry analysis}

Methanolic extract (CJLE) with a concentration of 25 $\mathrm{mg} / \mathrm{ml}$ was used for GC-MS. This method was adopted from Das et al. (2014) and Labar et al. (2019) with a slight modification. One microliter of CJLE was injected in split mode in the instrument (GCMS-QP2010 Plus). Injection temperature was $260^{\circ} \mathrm{C}$ and the interface temperature was set to $270^{\circ} \mathrm{C}$. Ion source temperature was adjusted to $230{ }^{\circ} \mathrm{C}$. Helium was used as carrier gas. Total flow rate was $16.3 \mathrm{ml} \mathrm{min}^{-1}$ and the column flow rate was $1.21 \mathrm{ml} \mathrm{min}^{-1}$. Mass spectra were recorded at 5 scan $\mathrm{s}^{-1}$ with a scanning range of $40-650 \mathrm{~m} / \mathrm{z}$. Quantification of compounds was done on the bases of their peak areas. The data obtained from GCMS analysis were further analyzed from available literature.

\section{Studies on biosynthesis pathways of different terpenoids found in CJLE}

Studies on biosynthesis pathways of different compounds detected in GC-MS were done by reviewing several literatures and databases (The Kyoto Encyclopedia of Genes and Genomes database 2020 and The PubChem 2020).

\section{Results}

\section{Gas chromatography-mass spectrometry analysis}

Total of fifty peaks were found in the chromatogram (Table 1; Fig. 1) showing forty-seven different compounds where twenty-nine compounds are reported natural anti-inflammatory agents with a summative value of $83.96 \%$ in total area. The major anti-inflammatory molecules detected in the extract were squalene (27.25\%), lupeol (17.26\%), diethyl phthalate (5.11\%), vitamin E (5.01\%), and patchouli alcohol (3.49\%) along with other twenty-four anti-inflammatory compounds contributing a total share over eighty-three percentage of peak area (shown in Table 2; Fig. 2) where some of them are reported as pain relievers and as anti-arthritic.

Compounds are arranged on the bases of their chemical groups regarding their biosynthesis pathways, which are mainly sesquiterpenes, triterpenes, diterpene, monoterpenes, tocopherols, phthalate esters, cannabinoid, and others (Table 2; Fig. 3). Interestingly, more than seventyfour percentage of the extract belongs to terpenoids and their derivatives. Total of twenty compounds (patchoulol, alpha-, and gamma-patchoulene, alpha-gurjunene, caryophyllene, isoledene, etc.) with $19.58 \%$ percentage of total peak area belong to the class sesquiterpene while triterpenoids like squalene, oxidosqualene, methyl commate $\mathrm{B}$, and lupeol have occupied $50.02 \%$ of peak area (shown in Fig. 3). Furthermore, five compounds are present from the group monoterpenes (including their derivatives as linalyl acetate) while sclareol (diterpene), CB-86 (cannabinoid), and vitamin E (tocopherol) are lone representatives of their chemical groups having rich bioactivities. A total of $7.52 \%$ area belongs to phthalate esters where two of them are reported bioactive but their biosynthesis or biodegradation pathway in this particular plant is not clear due to absence of previous reports and precursors or intermediates in our result.

\section{Studies on biosynthesis pathways of different terpenoids found in CJLE}

Triterpenes, sesquiterpenes, monoterpenes, and tocopherol are major groups of bioactive components found in plant bodies where their pathways are closely related with each other as isopentyl diphosphate (IPP) and dimethylallyl diphosphate (DMAPP) play the role of precursors in their biosynthesis (Fig. 4). The biosynthesis pathway of terpenoids in plants involves and regulates a number of pathways, where bioactive compounds like squalene, lupeol, vitamin E, patchouli alcohol, eucalyptol, and linalyl acetate are synthesized which have been found in CJLE.

\section{Triterpenoids}

Triterpenoid (50.02\%) is the major group of compounds reported in this GC-MS analysis of CJLE. Squalene, one of the triterpenes found in CJLE, is involved as a common precursor for synthesis of various hormones in animals and sterols in plants. Moreover, squalene, itself is a major bioactive compound having anti-inflammatory property (Table 2). Oxidosqualene, also named as epoxysqualene and (3S)-2,3-epoxy-2,3-dihydrosqualene, is another triterpene compound found in our GC-MS as 
Table 1 GC-MC result of Camellia japonica leaf extract

\begin{tabular}{|c|c|c|c|c|}
\hline Peak index & R. time & Area & Area\% & Name \\
\hline 1 & 7.368 & 493233 & 1.18 & Eucalyptol \\
\hline 2 & 10.733 & 274998 & 0.66 & Linalyl acetate \\
\hline 3 & 11.342 & 182020 & 0.43 & 1,7,7-TRIMETHYLBICYCLO[2.2.1]HEPT-2-YL ACETA \\
\hline 4 & 12.157 & 751582 & 1.79 & 3-CYCLOHEXENE-1-METHANOL, .ALPHA...ALPHA., \\
\hline 5 & 12.753 & 129266 & 0.31 & EPIGLOBULOL \\
\hline 6 & 13.026 & 794979 & 1.89 & 1H-CYCLOPROP[E]AZULENE, 1A,2,3,4,4A,5,6,7B-OC \\
\hline 7 & 13.207 & 555776 & 1.32 & Caryophyllene \\
\hline 8 & 13.360 & 551887 & 1.32 & Isoledene \\
\hline 9 & 13.567 & 93953 & 0.22 & 3-Chloropropane-1,2-diol, bis(tert-butyldimethylsilyl) ethe \\
\hline 10 & 13.639 & 93299 & 0.22 & Seychellene \\
\hline 11 & 13.737 & 59132 & 0.14 & NEOALLOOCIMENE \\
\hline 12 & 13.792 & 65085 & 0.16 & 1H-3a,7-Methanoazulene, 2,3,6,7,8,8a-hexahydro-1,4,9,9-t \\
\hline 13 & 13.881 & 65370 & 0.16 & 1H-3a,7-Methanoazulene, octahydro-1,9,9-trimethyl-4-met \\
\hline 14 & 14.116 & 140615 & 0.34 & BICYCLO[7.2.0]UNDEC-4-ENE, 4,11,11-TRIMETHYL- \\
\hline 15 & 14.439 & 118763 & 0.28 & $(1 \mathrm{~S}, 2 \mathrm{E}, 6 \mathrm{E}, 10 \mathrm{R})-3,7,11,11$-Tetramethylbicyclo[8.1.0] undec \\
\hline 16 & 15.137 & 329737 & 0.79 & (1aR,3aS,7S,7aS,7bR)-1,1,3a,7-Tetramethyldecahydro-1H- \\
\hline 17 & 15.224 & 255742 & 0.61 & 1H-Cycloprop[e]azulen-7-ol, decahydro-1,1,7-trimethyl-4- \\
\hline 18 & 15.286 & 2142686 & 5.11 & 1,2-BENZENEDICARBOXYLIC ACID, DIETHYL ESTE \\
\hline 19 & 15.447 & 757801 & 1.81 & Epicurzerenone \\
\hline 20 & 15.531 & 308410 & 0.74 & Chenodiol \\
\hline 21 & 15.617 & 15884 & 0.04 & Unidentified compound \\
\hline 22 & 15.673 & 412507 & 0.98 & 1,1,4,7-Tetramethyldecahydro-1H-cyclopropa[e]azulene-4, \\
\hline 23 & 15.787 & 716851 & 1.71 & TRIDEUTERIOMETHYL 10-EPOXY-7-ETHYL-3,11-DI \\
\hline 24 & 15.988 & 768032 & 1.83 & METHYL (3-OXO-2-PENTYLCYCLOPENTYL)ACETA \\
\hline 25 & 16.159 & 1287600 & 3.07 & 1-(4-ISOPROPYLPHENYL)-2-METHYLPROPYL ACET \\
\hline 26 & 16.248 & 79006 & 0.19 & 1-(4-ISOPROPYLPHENYL)-2-METHYLPROPYL ACET \\
\hline 27 & 16.345 & 544685 & 1.30 & 2-PENTEN-1-OL, 5-(2,3-DIMETHYLTRICYCLO[2.2.1.0 \\
\hline 28 & 16.394 & 1466093 & 3.49 & Patchouli alcohol \\
\hline 29 & 16.590 & 257277 & 0.61 & 1-Naphthalenepropanol, .alpha.-ethenyldecahydro-2-hydro \\
\hline 30 & 16.651 & 187453 & 0.45 & (3aR,4R,7R)-1,4,9,9-Tetramethyl-3,4,5,6,7,8-hexahydro-2 \\
\hline 31 & 16.822 & 938511 & 2.24 & Santalol, E-cis,epi-.beta.- \\
\hline 32 & 16.915 & 104923 & 0.25 & 2-FURANMETHANOL, 5-ETHENYLTETRAHYDRO-.A \\
\hline 33 & 17.169 & 498732 & 1.19 & 4,8-DIMETHYL-3,8-NONADIEN-2-ONE \\
\hline 34 & 17.367 & 245089 & 0.58 & ACETYL CEDRENE \\
\hline 35 & 17.609 & 152712 & 0.36 & 1H-Benzocyclohepten-7-ol, 2,3,4,4a,5,6,7,8-octahydro-1,1 \\
\hline 36 & 17.941 & 346720 & 0.83 & Neophytadiene \\
\hline 37 & 18.129 & 184873 & 0.44 & 4,6,6,7,8,8-HEXAMETHYL-1,3,4,6,7,8-HEXAHYDROC \\
\hline 38 & 18.212 & 185266 & 0.44 & 7-ACETYL-1,1,3,4,4,6-HEXAMETHYL TETRALIN \\
\hline 39 & 19.882 & 666930 & 1.59 & Ethylene brassylate \\
\hline 40 & 20.105 & 66589 & 0.16 & CYCLODODECASILOXANE, TETRACOSAMETHYL- \\
\hline 41 & 22.495 & 86863 & 0.21 & SILICONE OIL \\
\hline 42 & 23.572 & 75245 & 0.18 & SILICONE OIL \\
\hline 43 & 24.252 & 1011139 & 2.41 & Bis(2-ethylhexyl) phthalate \\
\hline 44 & 26.522 & 11434137 & 27.25 & Squalene \\
\hline
\end{tabular}


Table 1 GC-MC result of Camellia japonica leaf extract (Continued)

\begin{tabular}{lllll}
\hline Peak index & R. time & Area & Area\% & Name \\
\hline 45 & 27.528 & 178555 & 0.43 & CB-86 \\
46 & 27.664 & 230045 & 0.55 & SOLANESOL \\
47 & 27.796 & 523171 & 1.25 & Oxirane, 2,2-dimethyl-3-(3,7,12,16,20-pentamethyl-3,7,11, \\
48 & 2100440 & 5.01 & Vitamin E \\
49 & 30.688 & 1787264 & 4.26 & METHYL COMMATE B \\
50 & 36.935 & 7241879 & 17.26 & Lupeol \\
\hline
\end{tabular}

oxirane, 2,2-dimethyl-3-(3,7,12,16,20-pentamethyl-3,7,11, 15,19-heneicosapentaenyl)-, (all-E)-. It is actually an intermediate in triterpenoid biosynthesis pathway which is produced from squalene by the enzyme squalene mono-oxygenase (E.C. 1.14.14.17) (Fig. 5). Another major triterpene and anti-inflammatory compound detected by our GC-MS analysis is lupeol, which is present in high amount (17.26\%) and famous for its wide range of bioactivities. Methyl commate $\mathrm{B}\left(\mathrm{C}_{31} \mathrm{H}_{50} \mathrm{O}_{3}\right)$ is also an anti-inflammatory triterpene (Table 2) present in CJLE, which is actually a methyl ester of comic acid B. Methyl esterification may occur due to exposure of sample to methyl alcohol during extraction. Both lupeol and methyl commate B are biosynthesized in the same pathway where degradation of squalene occurs. Furthermore, step by step enzymatic reactions involved in the formation of

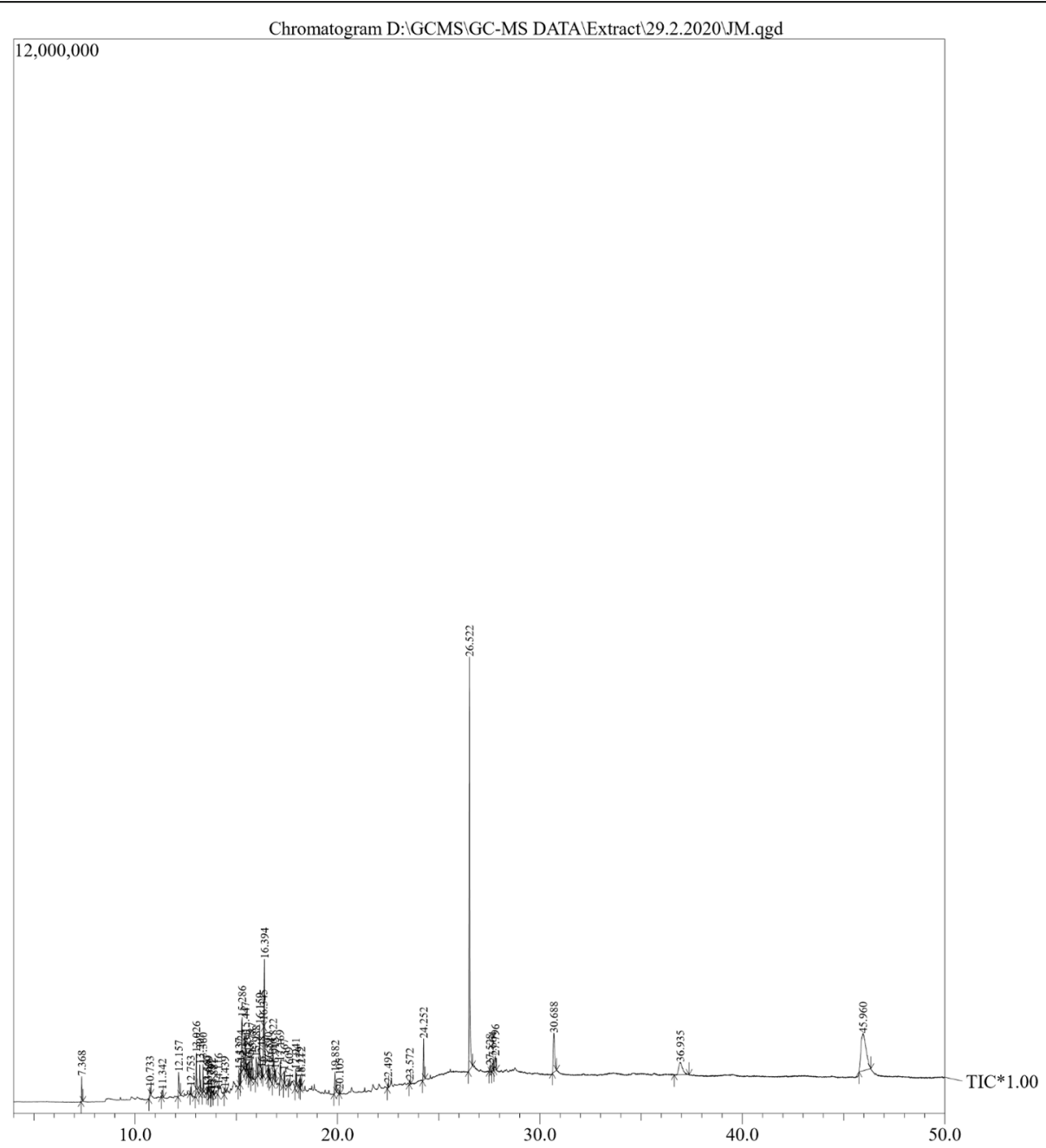

Fig. 1 GC-MS chromatogram of Camellia japonica leaf extract 
Table 2 Type of compounds present in Camellia japonica leaf extract and anti-inflammatory compounds in it

\begin{tabular}{|c|c|c|c|}
\hline Peak index & Camellia japonica leaf compounds & Type & Area\% \\
\hline 1 & Eucalyptol (Juergens et al. 2003) & Monoterpene & 1.18 \\
\hline 2 & Linalyl acetate (Peana et al. 2002) & Monoterpene & 0.66 \\
\hline 3 & 1,7,7-trimethylbicyclo[2.2.1]hept-2-yl acetate (Yang et al. 2014) & Monoterpene & 0.43 \\
\hline 4 & 3-cyclohexene-1-methanol, .alpha.,.alpha.,4... (Held et al. 2007) & Monoterpene & 1.79 \\
\hline 5 & Epiglobulol (Jayaprakash et al. 2019) & Sesquiterpene & 0.31 \\
\hline 6 & 1 h-cycloprop[e]azulene, 1A,2,3,4,4A,5,6,7B-oct... (Rajput et al. 2018) & Sesquiterpene & 1.89 \\
\hline 7 & Caryophyllene (Fernandes et al. 2007) & Sesquiterpene & 1.32 \\
\hline 8 & Isoledene & Sesquiterpene & 1.32 \\
\hline 10 & Seychellene (Raharjo et al. 2017) & Sesquiterpene & 0.22 \\
\hline 11 & Neoalloocimene (Pravdich-Neminskaya and Kachkov 1978) & Sesquiterpene & 0.14 \\
\hline 12 & 1H-3a,7-Methanoazulene, 2,3,6,7,8,8a-hexahydro-1,4,9,9-t & Sesquiterpene & 0.16 \\
\hline 13 & 1H-3a,7-Methanoazulene, octahydro-1,9,9-trimethyl-4-met & Sesquiterpene & 0.16 \\
\hline 14 & Bicyclo[7.2.0]undec-4-ene, 4,11,11-trimethyl-8 (Tambe et al. 1996) & Sesquiterpene & 0.34 \\
\hline 15 & (1S,2E,6E,10R)-3,7,11,11-Tetramethylbicyclo[8.1.0]undeca & Sesquiterpene & 0.28 \\
\hline 16 & (1AR,3AS,7S,7AS,7BR)-1,1,3a,7-Tetramethyldecahydro-1H- or maaliol (Sah et al. 2012) & Sesquiterpene & 0.79 \\
\hline 17 & $\begin{array}{l}\text { 1H-Cycloprop[E]azulen-7-ol, decahydro-1,1,7-trimethyl-4-m or (+)-spathulenol } \\
\text { (do Nascimento et al. 2018) }\end{array}$ & Sesquiterpene & 0.61 \\
\hline 18 & 1,2-benzenedicarboxylic acid, diethyl ester (Singh et al. 2012) & Phthalate ester & 5.11 \\
\hline 19 & Epicurzerenone (Makabe et al. 2006) & Sesquiterpene & 1.81 \\
\hline 22 & 1,1,4,7-Tetramethyldecahydro-1H-cyclopropa[e]azulene-4,7 & Sesquiterpene & 0.98 \\
\hline 23 & Trideuteriomethyl 10-epoxy-7-ethyl-3,11-dim & & 1.17 \\
\hline 24 & Methyl (3-oxo-2-pentylcyclopentyl)acetat... (Dang et al. 2008) & & 1.83 \\
\hline 27 & 2-penten-1-ol, 5-(2,3-dimethyltricyclo[2.2.1.02... (Bommareddy et al. 2019) & Sesquiterpene & 1.3 \\
\hline 28 & Patchouli alcohol (Li et al. 2011) & Sesquiterpene & 3.49 \\
\hline 29 & 1-Naphthalenepropanol, .alpha.-ethenyldecahydro-2-hydrox... (Tsai et al. 2018) & Diterpene & 0.61 \\
\hline 30 & (3AR,4R,7R)-1,4,9,9-Tetramethyl-3,4,5,6,7,8-hexahydro-2H... or cyperenone (Gupta and Shaw 2009) & Sesquiterpene & 0.45 \\
\hline 31 & Santalol, E-cis,epi-.beta.- & Sesquiterpene & 2.24 \\
\hline 32 & 2-furanmethanol, 5-ethenyltetrahydro-.a & Monoterpene & 0.25 \\
\hline 34 & Acetyl cedrene & Sesquiterpene & 0.58 \\
\hline 35 & 1H-Benzocyclohepten-7-ol, $\mathbf{2 , 3 , 4 , 4 A , 5 , 6 , 7 , 8 - o c t a h y d r o - 1 , 1 , \ldots . ~ o r ~ w i d d r o l ~ ( J i n ~ e t ~ a l . ~ 2 0 1 5 ) ~}$ & Sesquiterpene & 0.36 \\
\hline 36 & Neophytadiene (Bhardwaj et al. 2020) & Sesquiterpene & 0.83 \\
\hline 37 & 4,6,6,7,8,8-hexamethyl-1,3,4,6,7,8-hexahydrocy & & 0.44 \\
\hline 38 & 7-acetyl-1,1,3,4,4,6-hexamethyl tetralin & & 0.44 \\
\hline 39 & Ethylene brassylate (Kim et al. 2006) & & 1.59 \\
\hline 40 & Cyclododecasiloxane, tetracosamethyl- (Kumar et al. 2018) & & 0.16 \\
\hline 43 & Bis(2-ethylhexyl) phthalate (Mohammed et al. 2014) & Phthalate ester & 2.41 \\
\hline 44 & Squalene (Fernando et al. 2018) & Triterpene & 27.25 \\
\hline 45 & Cb-86 & Cannabinoid & 0.43 \\
\hline 46 & Solanesol (Yan et al. 2015) & Terpene-alcohol & 0.55 \\
\hline 47 & Oxirane, 2,2-dimethyl-3-(3,7,12,16,20-pentamethyl-3,7,11,1 & Triterpene & 1.25 \\
\hline 48 & Vitamin E (Jiang 2014) & Tocopherols & 5.01 \\
\hline 49 & Methyl commate B (Arora and Kumar 2018) & Triterpene & 4.26 \\
\hline 50 & Lupeol (Saleem 2009) & Triterpene & 17.26 \\
\hline
\end{tabular}




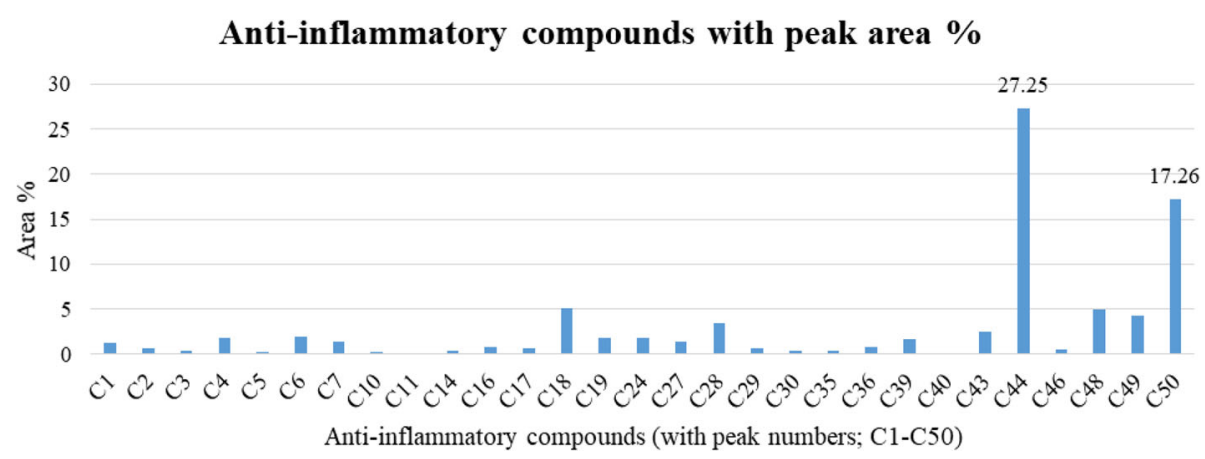

Fig. 2 Anti-inflammatory compounds of Camellia japonica leaf extract. C1-C50 = GC-MS detected compounds' peak numbers in order (Table 1)

lupeol and methyl commate B (Figs. 6 and 7) are described in the "Discussion" section.

\section{Sesquiterpenoids}

Patchouli alcohol (3.49\%), the major sesquiterpene present in this leaf extract, is a germacrene and synthesized from FPP by the enzyme patchoulol synthase (E.C. 4.2.3.70) (Fig. 8) (https://www.genome.jp/kegg/pathway. html). In the same pathway, nineteen other sesquiterpenes of the plant are also produced from FPP by different enzymes.

\section{Monoterpenoids}

Total of four monoterpene compounds have been found in our GC-MS result. Among them, the higher amount of monoterpene is terpinyl acetate or 3-cyclohexene-1methanol, .alpha.,.alpha.,4-trimethyl-, acetate (1.79\%) which is the acetate ester of alpha-terpineol synthesized from GPP by the enzyme alpha-terpineol synthase (E.C. 4.2.3.112). Another major monoterpene eucalyptol
(1.18\%) follows the same pathway which is synthesized from GPP by the enzyme 1,8-cineole synthase (E.C. 4.2.3.108). Linalyl acetate $(0.66 \%)$ is also a monoterpene which is the acetate ester of linalool. Biosynthesis of linalool by linalool synthase enzyme (E.C. 4.2.3.26) is also established in monoterpenoid biosynthesis pathway which is shown in Fig. 9.

\section{Vitamin E, sclareol, and solanesol}

According to our GC-MS result, vitamin E (5.01\%), more specifically alpha-tocopherol, is one of the major anti-inflammatory compound which is synthesized in ubiquinone and other terpenoid quinone biosynthesis pathway. Sclareol (0.61\%; a diterpene) and solanesol (0.55\%; a nonaprenol), two anti-inflammatory compounds (Table 2), are present in minute amounts in CJLE, but being lone representatives of their respective chemical groups and having relations with earlier mentioned terpenoids regarding biosynthesis pathways, they are included in this study. Like other terpenoids, both

\section{Major chemical groups in Camellia japonica leaf}

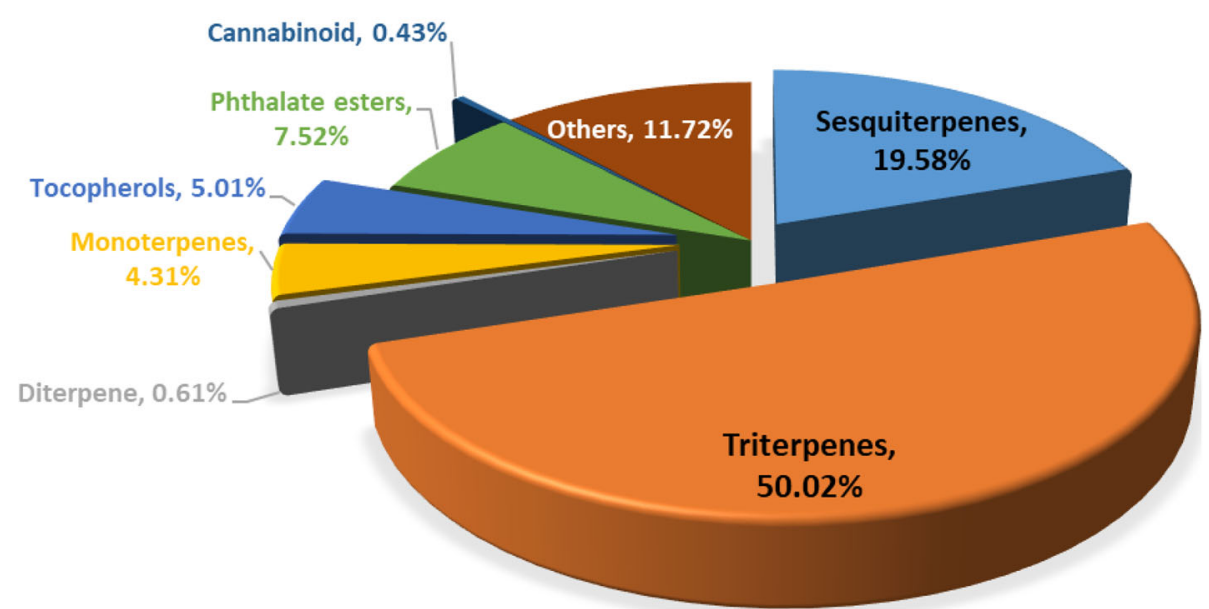

Fig. 3 Types of compounds on the basis of their biosynthesis in Camellia japonica leaf extract; majority of triterpenoids in Camellia japonica leaf 


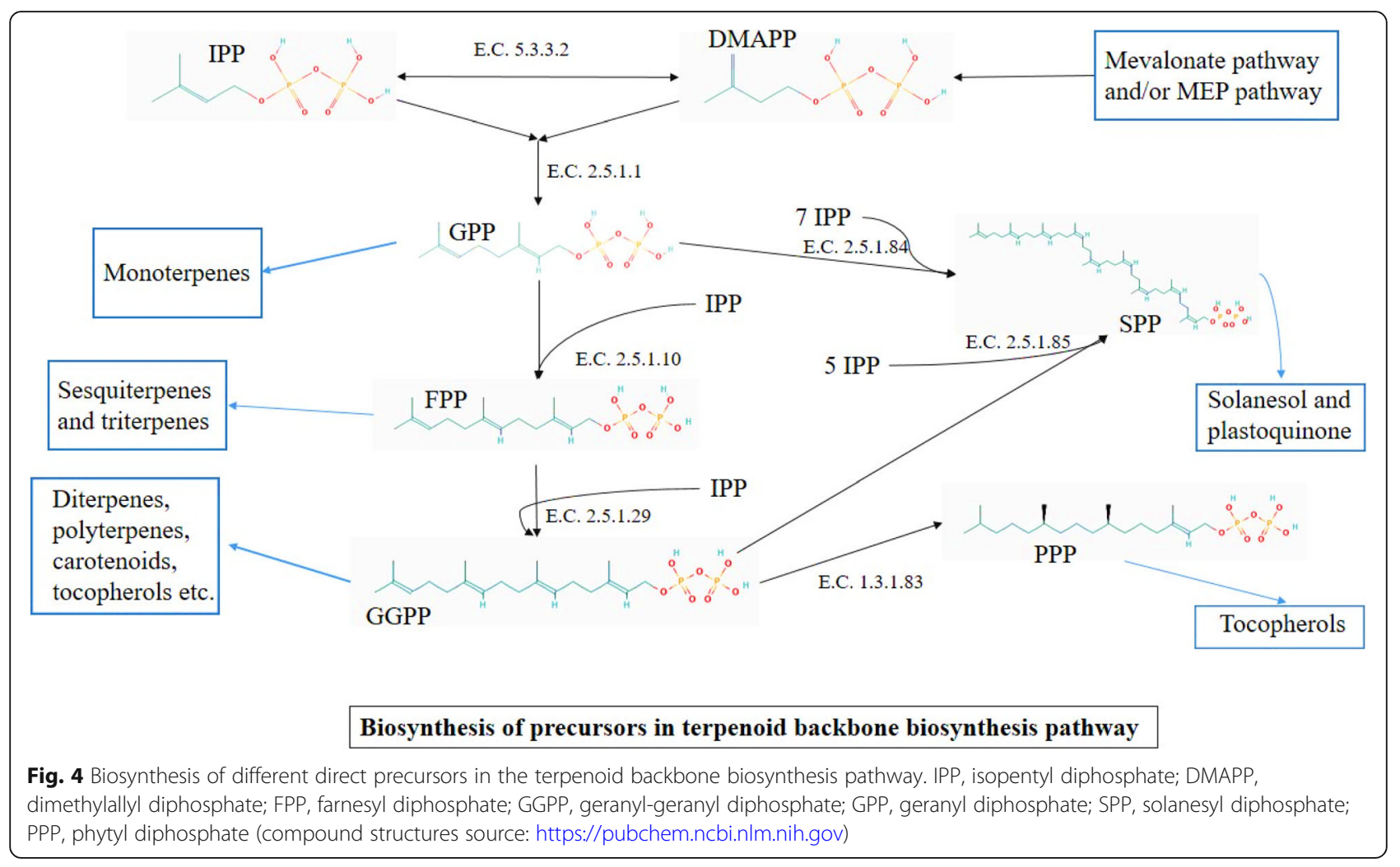

alpha-tocopherol (Fig. 10), sclareol, and solanesol (Fig. 11) are biosynthesized from IPP and DMAPP derived precursors in plastids through MEP metabolic pathway which is described in the "Discussion" section.

Figure 12 is designed as a brief diagram on biosynthesis pathway of all the abovementioned CJLE compounds found in the GC-MS result.

\section{Discussion}

Biosynthesis pathways are studied to investigate origin, precursors, intermediates, and breakdown products of different compounds, probable pathways of newly reported compounds having similar established structures, reactions, and relations between several compounds in individual plant bodies. In our research, we have used GC-

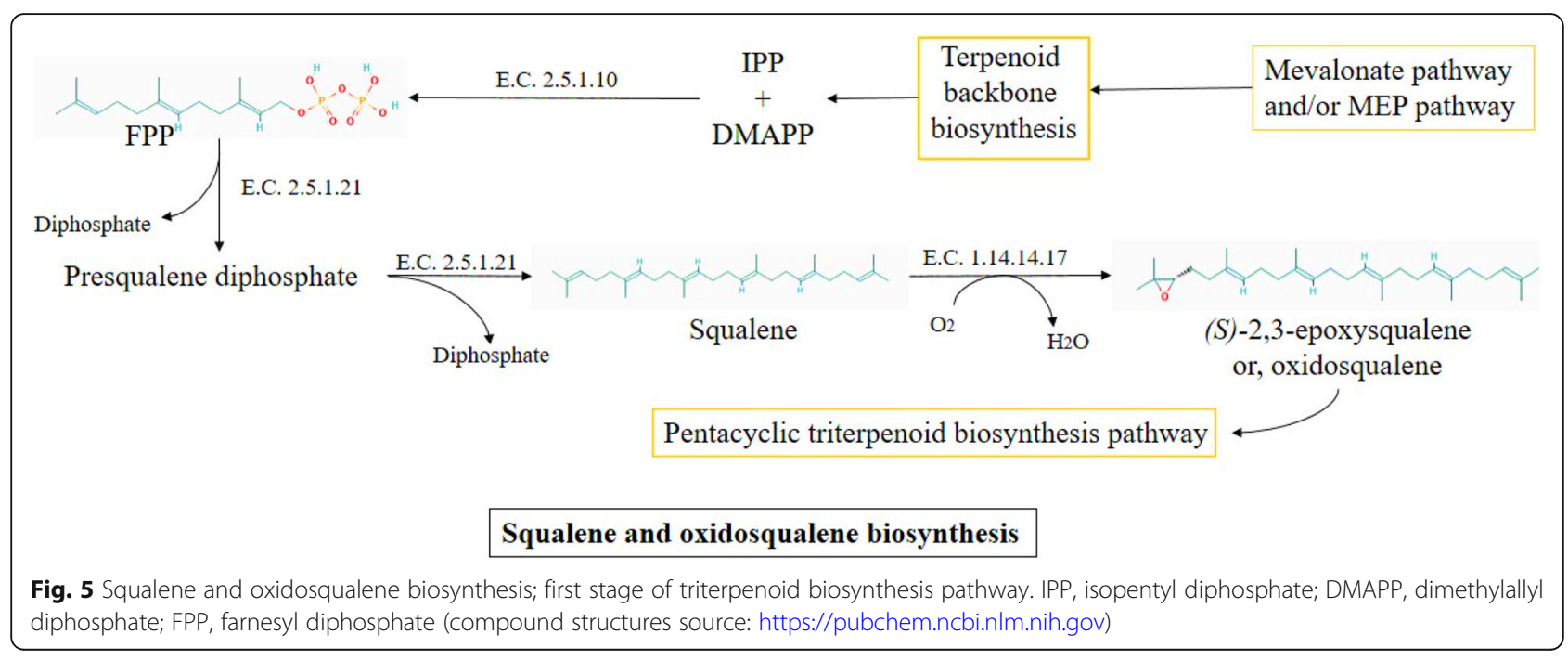




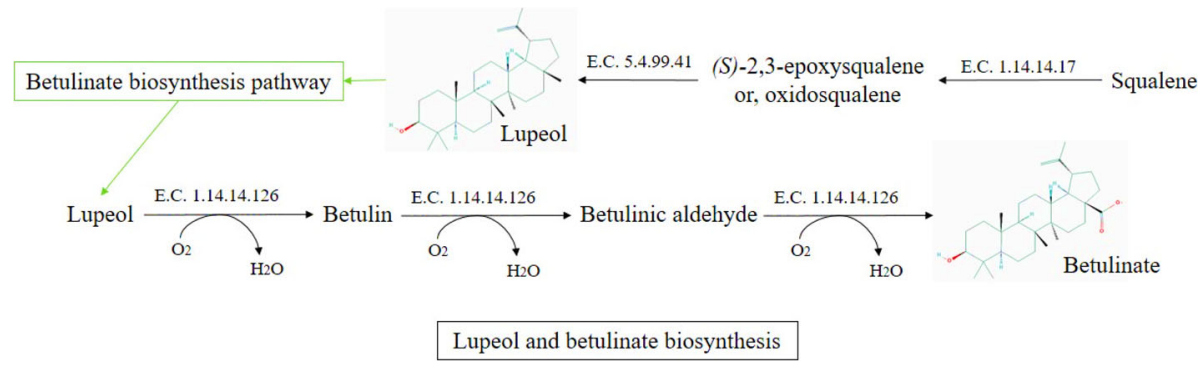

Fig. 6 Lupeol biosynthesis and degradation (common biosynthesis pathway for any pentacyclic triterpene) (compound structures source: https://pubchem.ncbi.nlm.nih.gov)

MS, one of the preliminary and first-step technique of metabolomics, to analyze the terpenoids present in Camellia japonica. Then studies on their biosynthesis pathways were carried out where several interactions and interrelations came out along with designs of probable biosynthesis pathways of unestablished metabolomes.

Wang et al. (2013), in their studies on biosynthesis pathway of terpenoid, proposed involvement of three different stages; firstly, the generation of $\mathrm{C} 5$ isopentyl diphosphate (IPP) precursor and its double bond isomer dimethylallyl diphosphate (DMAPP); secondly, the generation of direct precursors like geranyl diphosphate or GPP (for monoterpenes), farnesyl diphosphate or FPP (for triterpenes and sesquiterpenes), and geranylgeranyl diphosphate or GGPP (for diterpenes and tocopherols) (Fig. 4); and thirdly, biosynthesis and modification of terpenes via oxidation-reduction, acylation, glycosylation, and other reactions. In general, biosynthesis of sesquiterpene and triterpene takes place in the cytosol part of the cell while monoterpenes, tocopherols, and solanesol are synthesized inside the plastid just like chlorophylls and carotenoids in higher plants.
Triterpenes, in general, are produced from the precursor FPP which is derived from two IPP molecules and one DMAPP (McGarvey and Croteau 1995) by farnesyl diphosphate synthase through mevalonate pathway as shown in Fig. 4. Both squalene (27.25\%) and lupeol (17.26\%) are two abundant most compounds in this leaf extract which imparts anti-inflammatory activity to it. Squalene is produced from FPP by the enzyme squalene synthase (E.C. 2.5.1.21) (Fig. 5). In plants, squalene is metabolized by the enzyme squalene mono-oxygenase (E.C. 1.14.14.17) to produce (3S)-2,3-epoxy-2,3-dihydrosqualene or oxidosqualene (Wang et al. 2010) which is also present in our result. It then enters into pentacyclic triterpenoid biosynthesis pathway. Oxidosqualene can be converted into pentacyclic triterpenes like lupeol, alpha-amyrin, beta-amyrin, and several potentially bioactive phytosterols, an amazing number of structurally diverse backbones, including over hundred identified in plants (Wang et al. 2010) by oxidosqualene cyclase enzymes. Lupeol is a pharmacologically active pentacyclic and lupine type of triterpene. According to Saleem (2009), lupeol exhibits various pharmacological activities

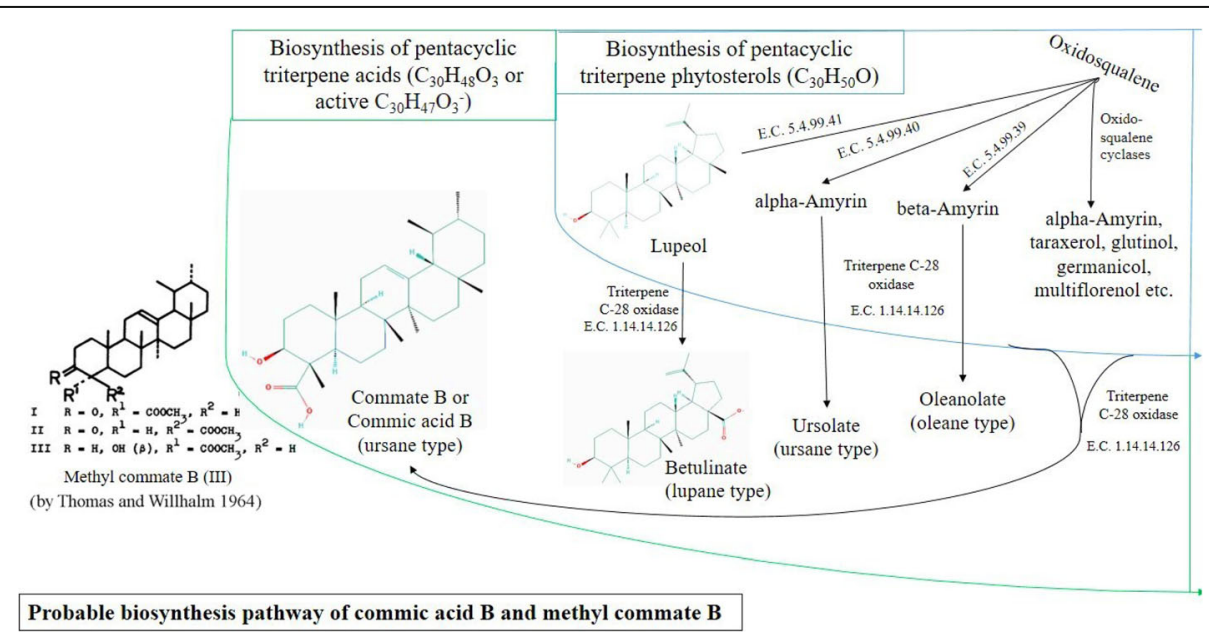

Fig. 7 Probable biosynthesis pathway of commic acid B and methyl commate B (compound structures source: https://pubchem.ncbi.nlm.nih.gov) 


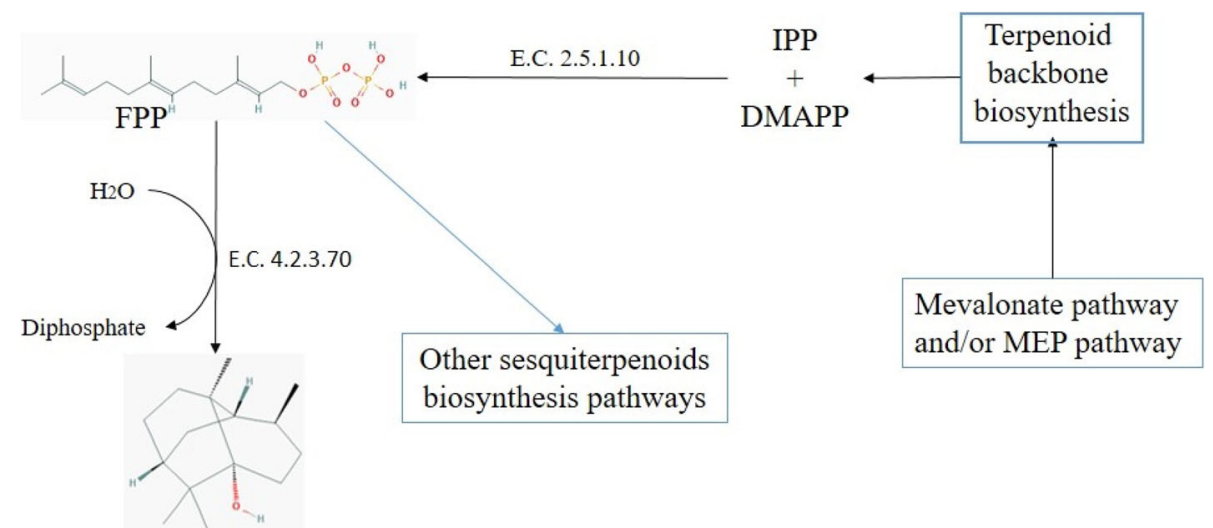

Patchouli alcohol (germacrene type sesquiterpene)

\section{Patchoulol and other sesquiterpenoids biosynthesis}

Fig. 8 Sesquiterpenoid biosynthesis pathway from FPP; i.e., patchouli alcohol. IPP, isopentyl diphosphate; DMAPP, dimethylallyl diphosphate; FPP, farnesyl diphosphate (compound structures source: https://pubchem.ncbi.nlm.nih.gov)

against inflammation (Table 2), cancer, arthritis, diabetes, heart diseases, renal toxicity, and hepatic toxicity. Lupeol has been extensively studied for its inhibitory effects on inflammation under in vitro and in animal models where it showed positive responses (Saleem 2009). Lupeol synthase (E.C. 5.4.99.41), an oxidosqualene cyclase, is a multifunctional enzyme that forms lupeol (Fig. 6) and other triterpene alcohols (like beta-amyrin). Sequence analysis suggests that lupeol synthase diverged from cycloartenol synthase after plants diverged from fungi and animals for which fungi and animals do not synthesize lupeol (Herrera et al. 1998), and presence of

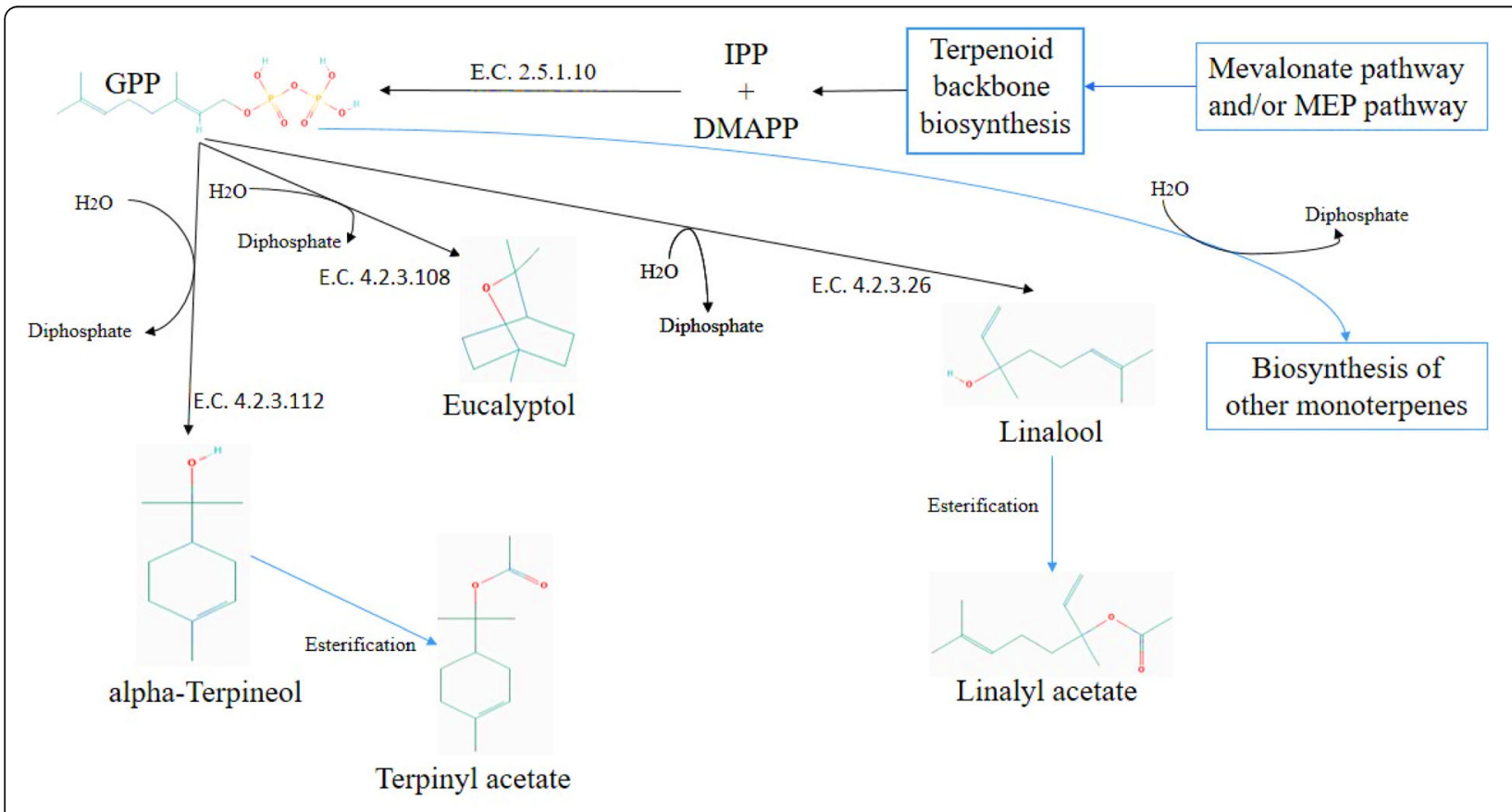

Monoterpene biosynthesis pathway; formation of terpinyl acetate, eucalyptol, linalyl acetate and other monoterpenes

Fig. 9 Monoterpene biosynthesis pathway; formation of terpinyl acetate, eucalyptol, linalyl acetate, and other monoterpenes. IPP, isopentyl diphosphate; DMAPP, dimethylallyl diphosphate; GPP, geranyl diphosphate (compound structures source: https://pubchem.ncbi.nlm.nih.gov) 


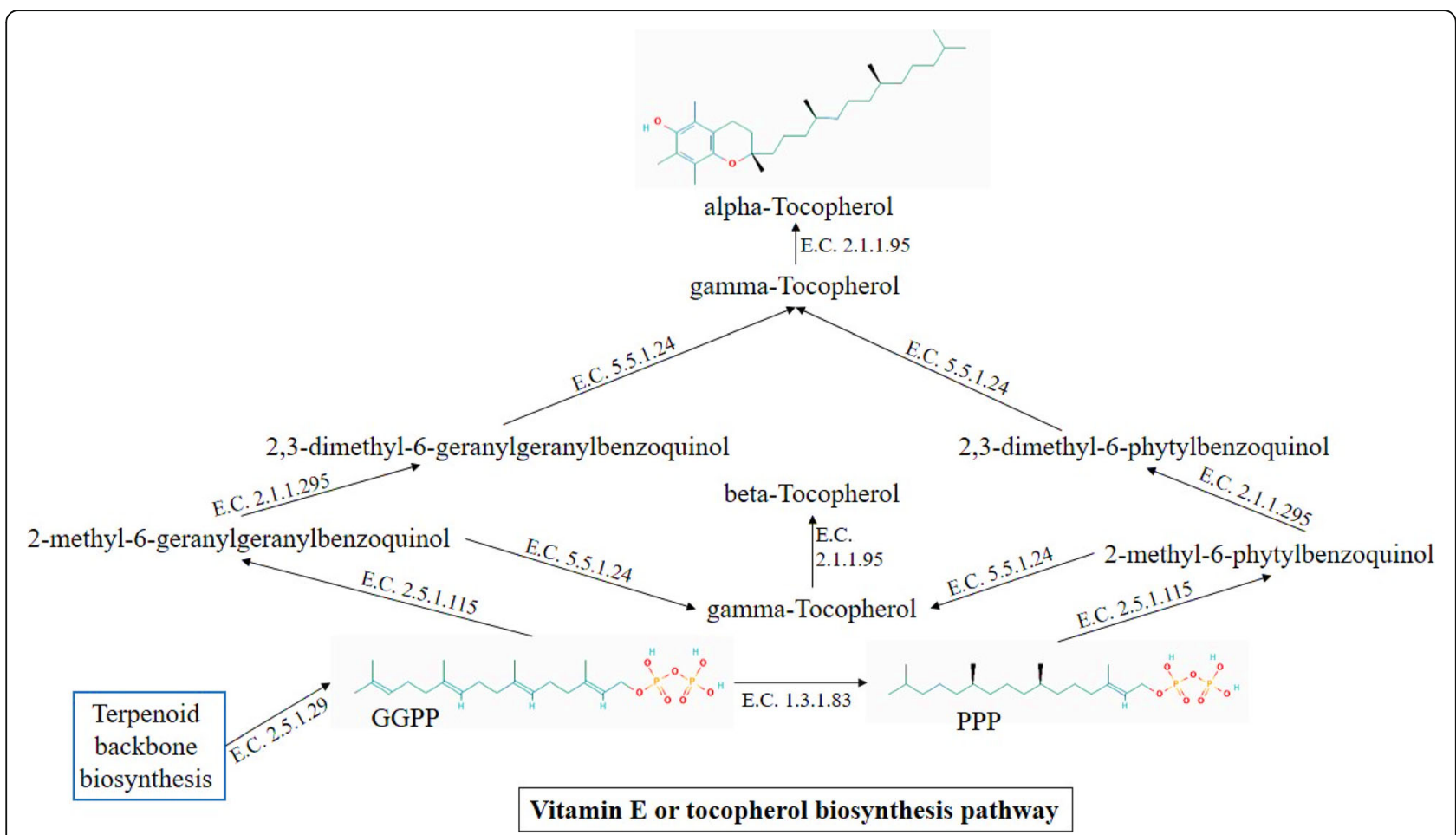

Fig. 10 Vitamin E or tocopherol biosynthesis pathway. GGPP, geranyl-geranyl diphosphate; PPP, phytyl diphosphate (compound structures source: https://pubchem.ncbi.nlm.nih.gov)

squalene, oxidosqualene, and lupeol together as major compounds has already proved the presence of lupeol synthase in this plant. According to Huang et al. (2012), lupeol then enters into betulinate biosynthesis pathway where after a series of oxidation process it converts into betulinate; $\mathrm{C}_{30} \mathrm{H}_{47} \mathrm{O}_{3}{ }^{-}$(parent compound betulinic acid; $\mathrm{C}_{30} \mathrm{H}_{48} \mathrm{O}_{3}$ ) by the enzyme lupeol-28-monooxygenase (E.C. 1.14.14.126). According to Saleem (2009), different fruits (olive, mango, and Japanese pear), aloe leaves, elm plant, and ginseng oil are the major source of lupeol. Lupeol was reported in Camellia seed oil (Akihisa et al. 1997) but there is no previous report that discloses the presence of lupeol in the leaves of Camellia japonica. Methyl commate B is another major triterpene found in CJLE. Unfortunately, there is no report on biosynthesis pathway for methyl commate $\mathrm{B}$ or comic acid $\mathrm{B}$ but the structure of comic acid $\mathrm{B}\left(\mathrm{C}_{30} \mathrm{H}_{48} \mathrm{O}_{3}\right)$ is very much close to other pentacyclic triterpene acids like betulinic acid (lupeol derived), ursolic acid (alpha-amyrin derived), and oleanolic acid (beta-amyrin derived) which have the same chemical formula, that is $\mathrm{C}_{30} \mathrm{H}_{48} \mathrm{O}_{3}$, and most of them are seen potentially medicinal in nature. According to the terpenoid biosynthesis pathway, these $\mathrm{C}_{30} \mathrm{H}_{48} \mathrm{O}_{3}$ pentacyclic triterpene acids or active $\mathrm{C}_{30} \mathrm{H}_{47} \mathrm{O}_{3}{ }^{-}$(ionized) are usually produced from squalene derived pentacyclic triterpene phytosterols or secondary alcohol $\left(\mathrm{C}_{30} \mathrm{H}_{50} \mathrm{O}\right)$ by oxidoreductase enzymes which are functionally same and termed as triterpene $\mathrm{C}-28$ oxidase (E.C. 1.14.14.126). According to our interpretation, the same reactions should be followed in comic acid B formation from its specific phytosterol precursor. However, methyl commate B is not derived from lupeol as it is not a lupine type of triterpene but an ursane (Thomas and Willhalm 1964). Established triterpene biosynthesis pathways and their interactions have helped us to design a probable pathway for comic acid B synthesis (Fig. 7) where a squalene derived $\mathrm{C}_{30} \mathrm{H}_{50} \mathrm{O}$ phytosterol (the precursor comic acid B) must be present as a precursor just like other triterpenes. But, in our GC-MS result, it is either absent or not detected as a precursor, thus, Camellia japonica must be subjected for further research to find responsible genes and enzymes behind biosynthesis of this compound.

After triterpene, the second most major chemical group in this plant extract is sesquiterpene including twenty different compounds, which are again produced from the precursor FPP following the mevalonate pathway. After terpenoid backbone biosynthesis and before squalene synthesis, FPP gets involved in the sesquiterpenoid biosynthesis pathway where it converts into a number of antiinflammatory sesquiterpenes (Table 2) including patchouli alcohol.

Four monoterpene compounds have also been found in our GC-MS result as described earlier. Monoterpenes in 

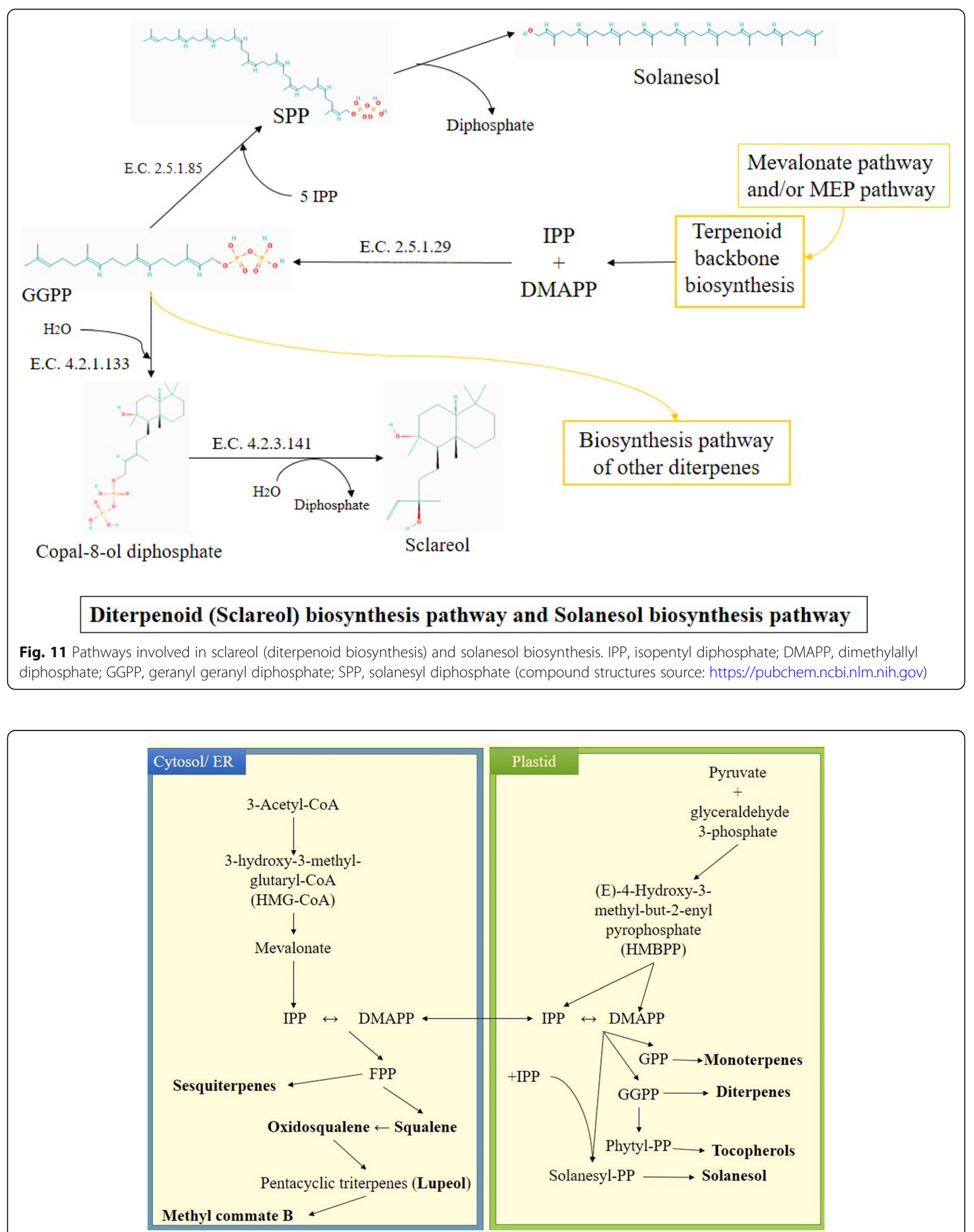

Fig. 12 Single diagram showing biosynthesis of major CJLE compounds. IPP, isopentyl diphosphate; DMAPP, dimethylallyl diphosphate; FPP, farnesyl diphosphate; GGPP, geranyl-geranyl diphosphate; GPP, geranyl diphosphate; PP, diphosphate 
plants are biosynthesized from GPP which is produced by the enzyme geranyl pyrophosphate synthase (E.C. 2.5.1.1) from one IPP and one DMAPP molecule which further produces monoterpenes by GPP diphosphate-lyases (Fig. 4) inside the plastid (Davis and Croteau 2000).

After FPP and GPP, GGPP is the main precursor in this plant as it converts into vitamin E, another major compound detected in CJLE. This precursor, itself is synthesized from IPP and DMAPP (Wang et al. 2013) like other terpenoid precursors which proves IPP and DMAPP as important factors that help us to understand interrelations between different terpenes over their biosynthesis. Moreover, enzyme geranyl diphosphate synthase (E.C. 2.5.1.29) forms GGPP which further converts into phytyl diphosphate or PPP (Fig. 4) by enzyme geranyl reductase (E.C. 1.3.1.83) to synthesize vitamin E. After completing a series of reactions, tocopherol or vitamin $E$ is synthesized where 2-methyl-6-phytylbenzoquinol (E.C. 2.5.1.115) and 2,3-dimethyl-6-phytylbenzoquinol (E.C. 2.1.1.295) take part in order as intermediates (Fig. 10). Another pathway of tocopherol biosynthesis is reported in plants where the same enzymatic reactions occur and GGPP converts directly into vitamin E without forming PPP (https://www.genome.jp/kegg/pathway.html). Biosynthesis of chlorophyll, carotenoids, plastoquinone, ubiquinone, solanesol, and diterpenoid like sclareol is also initiated by the same precursor GGPP. GGPP converts into copal-8-ol diphosphate (E.C. 4.2.1.133) which further produces sclareol (E.C. 4.2.3.141) as shown in Fig. 11. Solanesol, another terpenoid (a non-cyclic terpene alcohol) detected in CJLE, is synthesized from GGPP following the same three-stage terpenoid biosynthesis pathway of Wang et al. (2013). According to Yan et al. 2017, solanesyl diphosphate (SPP), the precursor of solanesol and plastoquinone, is synthesized from IPP, DMAPP, GPP, FPP, and GGPP by solanesyl diphosphate synthase (Fig. 4).

Some phthalate esters were also detected but they are already reported as chemical contaminants from laboratorial plastic tools (Reid et al. 2007), thus, further research is needed to establish their origin in this extract.

Moreover, natural products are still the most successful source of biologically active lead compounds in drug discovery (Atanasov et al. 2015) and there are some cases where the crude extract is more active than the isolated pure compound, e.g., the extract of Artemisia апnиa has more potent antimalarial properties than its pure natural product, artemisinin (De Donno et al. 2012) and our CJLE can be an example of this hypothesis too as we have found many anti-inflammatory compounds from different chemical groups where not only a few of triterpenes in higher amounts are responsible but also a number of compounds from sesquiterpene, monoterpene, tocopherol, diterpene biosynthesis pathways are there which also exhibits the same property.

\section{Conclusion}

Ongoing anti-inflammatory assays, other experiments, and gene sequencing studies are needed to confirm this metabolite-based pathway study and to find out the key enzymatic genes behind the synthesis of those antiinflammatory terpenoids found in CJLE. Herbal medications are becoming popular day by day because of their relatively few side effects, and our GC-MS analysis suggests not only as an ornamental plant but also this plant should be cultivated vigorously in this region to use the leaves as anti-inflammatory herbal formulations. Moreover, twenty-nine anti-inflammatory compounds with a share of more than eighty-three percentage area in Camellia japonica leaf extract; large peaks of metabolites leading by bioactive triterpenoids like squalene and lupeol (which can be isolated to use in pharmaceutical industries as this research has shown their abundance in Camellia japonica leaf); abundance of novel anticancer and anti-inflammatory medicinal compound lupeol with $17.26 \%$ peak area; and design of unexplored biosynthesis pathway of common plant component methyl commate B through metabolomics; are the key outcomes and highlights of the study.

\section{Abbreviations}

CJLE: Camellia japonica leaf extract; DMAPP: Dimethylallyl diphosphate;

FPP: Farnesyl diphosphate; GC-MS: Gas chromatography-mass spectrometry; GGPP: Geranylgeranyl diphosphate; GPP: Geranyl diphosphate; IPP: Isopentyl diphosphate; SPP: Solanesyl diphosphate; PPP: Phytyl diphosphate

\section{Acknowledgements}

Not applicable

Authors' contributions

All authors contributed to the study conception and design. Material preparation, data collection, and analysis were performed by SM, AG, and $M B$. The first draft of the manuscript was written by SM and all authors commented on previous versions of the manuscript. All authors read and approved the final manuscript.

Funding

Not applicable

Availability of data and materials

All data analyzed during this study are included in this article.

Ethics approval and consent to participate

Not applicable.

Consent for publication

Not applicable.

Competing interests

The authors declare that they have no competing interests.

Received: 5 June 2020 Accepted: 14 August 2020

Published online: 27 August 2020

References

Akihisa T, Yasukawa K, Kimura Y, Si T, Yamanouchi S, Tamura T (1997) Triterpene alcohols from camellia and sasanqua oils and their anti-inflammatory effects. Chem Pharm Bull 45(12):2016-2023 
Arora S, Kumar G (2018) Screening of bioactive compounds from leaf of Cenchrus ciliaris L. from Thar region of Rajasthan, India. Int J Pharm Sci Res 9(5):18781885

Atanasov AG, Waltenberger B, Pferschy-Wenzig EM, Linder T, Wawrosch C, Uhrin P, Temml V, Wang L, Schwaiger S, Heiss EH, Rollinger JM (2015) Discovery and resupply of pharmacologically active plant-derived natural products: a review. Biotechnol Adv 33(8):1582-1614

Bhardwaj M, Sali VK, Mani S, Vasanthi HR. Neophytadiene from Turbinaria ornata suppresses LPS-induced inflammatory response in RAW 264.7 Macrophages and Sprague Dawley Rats. Inflammation. 2020 Jan 24:1-4.

Bommareddy A, Brozena S, Steigerwalt J, Landis T, Hughes S, Mabry E, Knopp A, VanWert AL, Dwivedi C (2019) Medicinal properties of alpha-santalol, a naturally occurring constituent of sandalwood oil. Nat Prod Res 33(4):527-543

Dang HT, Lee HJ, Yoo ES, Hong J, Bao B, Choi JS, Jung JH (2008) New jasmonate analogues as potential anti-inflammatory agents. Bioorg Med Chem 16(24): 10228-10235

Das S, Vasudeva N, Sharma S (2014) Chemical composition of ethanol extract of Macrotyloma uniflorum (lam.) Verdc. Using GC-MS spectroscopy. Organ Med Chem Lett 4(1):13

Davis EM, Croteau R. Cyclization enzymes in the biosynthesis of monoterpenes, sesquiterpenes, and diterpenes. InBiosynthesis 2000 (pp. 53-95). Springer, Berlin, Heidelberg.

De Donno A, Grassi T, Idolo A, Guido M, Papadia P, Caccioppola A, Villanova L, Merendino A, Bagordo F, Fanizzi FP (2012) First-time comparison of the in vitro antimalarial activity of Artemisia annua herbal tea and artemisinin. Trans R Soc Trop Med Hyg 106(11):696-700

do Nascimento KF, Moreira FM, Santos JA, Kassuya CA, Croda JH, Cardoso CA, do Carmo Vieira M, Ruiz AL, Foglio MA, de Carvalho JE, Formagio AS. Antioxidant, anti-inflammatory, antiproliferative and antimycobacterial activities of the essential oil of Psidium guineense Sw. and spathulenol. Journal of ethnopharmacology. 2018 Jan 10;210:351-8.

Fernandes ES, Passos GF, Medeiros R, da Cunha FM, Ferreira J, Campos MM Pianowski LF, Calixto JB (2007) Anti-inflammatory effects of compounds alpha-humulene and (-)-trans-caryophyllene isolated from the essential oil of Cordia verbenacea. Eur J Pharmacol 569(3):228-236

Fernando IP, Sanjeewa KK, Samarakoon KW, Lee WW, Kim HS, Jeon YJ (2018) Squalene isolated from marine macroalgae Caulerpa racemosa and its potent antioxidant and anti-inflammatory activities. J Food Biochem 42(5):e12628

Gupta M, Shaw BP (2009) Uses of medicinal plants in Panchakarma Ayurvedic therapy. Indian J Tradit Knowl 8(3):372-378

Held S, Schieberle P, Somoza V (2007) Characterization of a-terpineol as an antiinflammatory component of orange juice by in vitro studies using oral buccal cells. J Agric Food Chem 55(20):8040-8046

Herrera JB, Bartel B, Wilson WK, Matsuda SP (1998) Cloning and characterization of the Arabidopsis thaliana lupeol synthase gene. Phytochemistry. 49(7):1905-1911

Huang L, Li J, Ye H, Li C, Wang H, Liu B, Zhang Y (2012) Molecular characterization of the pentacyclic triterpenoid biosynthetic pathway in Catharanthus roseus. Planta. 236(5):1571-1581

J Raharjo S, Mahdi C, Nurdiana N, Kikuchi T, Fatchiyah F (2017) In vitro and in silico: selectivities of Seychellene compound as candidate cyclooxygenase isoenzyme inhibitor on pre-osteoblast cells. Curr Enzym Inhib 13(1):2-10

Jayaprakash A, Johns AE, Haneef FK, Radhamany PM (2019) GC-MS analysis and in silico molecular docking studies of anti-inflammatory compounds from Thottea barberi (gamble) ding Hou root. Med Plants Int J Phytomedicines Related Industries 11(3):286-291

Jiang Q (2014) Natural forms of vitamin E: metabolism, antioxidant, and antiinflammatory activities and their role in disease prevention and therapy. Free Radic Biol Med 72:76-90

Jin S, Yun HJ, Jeong HY, Oh YN, Park HJ, Yun SG, Kim BW, Kwon HJ (2015) Widdrol, a sesquiterpene isolated from Juniperus chinensis, inhibits angiogenesis by targeting vascular endothelial growth factor receptor 2 signaling. Oncol Rep 34(3):1178-1184

Juergens UR, Dethlefsen U, Steinkamp G, Gillissen A, Repges R, Vetter H (2003) Anti-inflammatory activity of 1.8-cineol (eucalyptol) in bronchial asthma: a double-blind placebo-controlled trial. Respir Med 97(3):250-256

Kim SH, Nam GW, Lee HK, Moon SJ, Chang IS (2006) The effects of musk T on peroxisome proliferator-activated receptor [PPAR]-a activation, epidermal skin homeostasis and dermal hyaluronic acid synthesis. Arch Dermatol Res 298(6): 273-282

Konemann E. Trees and shrubs (Botanica's Pockets). Gorden Cheers. 2004.
Kumar D, Karthik M, Rajakumar R (2018) GC-MS analysis of bioactive compounds from ethanolic leaves extract of Eichhornia crassipes (Mart) Solms. And their pharmacological activities. Pharma Innov J 7(8):459-462

Labar R, Sarkar I, Sen A, Bhattacharya M (2019) Effect of solvent with varying polarities on phytochemical extraction from mature tea leaves and its evaluation using biochemical, antimicrobial and in-silico approaches. Int Res J Pharm 10(8):59-67

Lee HS, Choi JH, Cui L, Li Y, Yang JM, Yun JJ, Jung JE, Choi W, Yoon KC (2017) Anti-inflammatory and antioxidative effects of Camellia japonica on human corneal epithelial cells and experimental dry eye: in vivo and in vitro study. Invest Ophthalmol Visual Sci 58(2):1196-1207

Li YC, Xian YF, Ip SP, Su ZR, Su JY, He JJ, Xie QF, Lai XP, Lin ZX (2011) Antiinflammatory activity of patchouli alcohol isolated from Pogostemonis Herba in animal models. Fitoterapia. 82(8):1295-1301

Lim TK. Camellia japonica. Edible Medicinal and Non Medicinal Plants 2014 (pp. 764-776). Springer, Dordrecht.

Makabe H, Maru N, Kuwabara A, Kamo T, Hirota M (2006) Anti-inflammatory sesquiterpenes from Curcuma zedoaria. Nat Prod Res 20(7):680-685

Maroon JC, Bost JW, Maroon A (2010) Natural anti-inflammatory agents for pain relief. Surgical Neurol Int 1

McGarvey DJ, Croteau R (1995) Terpenoid metabolism. Plant Cell 7(7):1015

Mohammed MS, Ahmed WJ, Khalid HS, Mahmoud AM, Garelnabi EA (2014) Di(2'-ethylhexyl) phthalate and stigmasterol with anti-inflammatory effect from Cyperus rotundus L. Int J Pharm Chem Biol Sci 4(3):453-459

Onodera Kl, Hanashiro K, Yasumoto T (2006) Camellianoside, a novel antioxidant glycoside from the leaves of Camellia japonica. Biosci Biotechnol Biochem 70(8): 1995-1998

Peana AT, D’Aquila PS, Panin F, Serra G, Pippia P, Moretti MD (2002) Antiinflammatory activity of linalool and linalyl acetate constituents of essential oils. Phytomedicine. 9(8):721-726

Pravdich-Neminskaya TV, Kachkov AP (1978) Effect of Allo-ocimene on the healing of experimental soft tissue wounds. Bull Exp Biol Med 85(1):57-60

Rajput MS, Rathore D, Dahima R (2018) Anti-inflammatory potential of a-fenchol and a-gurjunene: an in vitro study. Panacea J Pharm Pharm Sci 7(3):129-135

Reid AM, Brougham CA, Fogarty AM, Roche JJ (2007) An investigation into possible sources of phthalate contamination in the environmental analytical laboratory. Int J Environ Anal Chem 87(2):125-133

Sah SP, Mathela CS, Chopra K (2012) Valeriana wallichii DC (maaliol chemotype): antinociceptive studies on experimental animal models and possible mechanism of action. Pharmacologia. 3:432-437

Saleem M (2009) Lupeol, a novel anti-inflammatory and anti-cancer dietary triterpene. Cancer Lett 285(2):109-115

Singh R, Dar SA, Sharma P (2012) Antibacterial activity and toxicological evaluation of semi purified hexane extract of Urtica dioica leaves. Res J Med Plants 6(2):123-135

Tambe Y, Tsujiuchi H, Honda G, Ikeshiro Y, Tanaka S (1996) Gastric cytoprotection of the non-steroidal anti-inflammatory sesquiterpene, $\beta$-caryophyllene. Planta Med 62(05):469-470

The Kyoto Encyclopedia of Genes and Genomes database https://www.genome. jp/kegg/pathway.html. Accessed on 20 May 2020.

The PubChem. https://pubchem.ncbi.nlm.nih.gov. Accessed on 18 May 2020.

Thomas AF, Willhalm B (1964) The triterpenes of Commiphora IV mass spectra and organic analysis $V$ mass spectroscopic studies and the structure of commic acids $a$ and B. Tetrahedron Lett 5(43):3177-3183

Tsai SW, Hsieh MC, Li S, Lin SC, Wang SP, Lehman CW, Lien CZ, Lin CC (2018) Therapeutic potential of sclareol in experimental models of rheumatoid arthritis. Int J Mol Sci 19(5):1351

Wang L, Fang X, Yang C, Li J, Chen X (2013) Biosynthesis and regulation of secondary terpenoid metabolism in plants. Scientia Sinica Vitae 43(12):1030-1046

Wang Z, Yeats T, Han H, Jetter R (2010) Cloning and characterization of oxidosqualene cyclases from Kalanchoe daigremontiana enzymes catalyzing up to 10 rearrangement steps yielding friedelin and other triterpenoids. J Biol Chem 285(39):29703-29712

Yan N, Liu Y, Gong D, Du Y, Zhang H, Zhang Z (2015) Solanesol: a review of its resources, derivatives, bioactivities, medicinal applications, and biosynthesis. Phytochem Rev 14(3):403-417

Yan, N., Liu, Y., Zhang, H., Du, Y., Liu, X. and Zhang, Z., 2017. Solanesol biosynthesis in plants. Molecules, 22(4), p.510.

Yang H, Zhao R, Chen H, Jia P, Bao L, Tang H (2014) Bornyl acetate has an antiinflammatory effect in human chondrocytes via induction of IL-11. IUBMB Life 66(12):854-859 
Yoon IS, Park DH, Kim JE, Yoo JC, Bae MS, Oh DS, Shim JH, Choi CY, An KW, Kim El, Kim GY (2017) Identification of the biologically active constituents of Camellia japonica leaf and anti-hyperuricemic effect in vitro and in vivo. Int J Mol Med 39(6):1613-1620

\section{Publisher's Note}

Springer Nature remains neutral with regard to jurisdictional claims in published maps and institutional affiliations.

Submit your manuscript to a SpringerOpen ${ }^{\circ}$ journal and benefit from:

- Convenient online submission

- Rigorous peer review

- Open access: articles freely available online

- High visibility within the field

- Retaining the copyright to your article

Submit your next manuscript at $\boldsymbol{\nabla}$ springeropen.com 